\title{
DIAGNOSIS OF REYE SYNDROME
}

\author{
MAKOTO YOSHINO, YASUYUKI ESAKI, SACHIHIKO SHIBUYA, \\ MASASHI YAMAMOTO, CHIHEI TANAKA, KYOKO KAWAKAMI, \\ FUMIO YAMASHITA*, NAOKI IKEJIRI AND KYUICHI TANIKAWA**
Department of Pediatrics and Child Health*, and Second Department of Intenal Medicine**, Kurume University School of Medicine, Kurume, 830, Japan

(Received for publication February 28, 1976)

\begin{abstract}
Three patients with acute encephalopathy and evidences of liver damage are presented. One of them was diagnosed as having Reye syndrome on the basis of light microscopic and electron microscopic observations on liver histology as well as clinical and laboratory evidences. Other 2 patients had liver histology different from that seen in Reye syndrome, despite they had clinical features and laboratory findings which were very similar to those of Reye syndrome. We propose from these experiences that diagnosis of Reye syndrome can only be made with histological evidence. Studies on the pathophysiology of other 2 patients who showed very similar metabolic alterations may given an alternative way to reach the essential pathogenesis of Reye syndrome, which may provide us with the possibility of nonhistologic diagnosis of Reye syndrome.
\end{abstract}

\section{INTRODUCTION}

Since a clinical and pathological condition which is characterized by encephalopathy and fatty degeneration of the viscera in infancy and childhood was first described by Reye and his coworkers (Reye et al., 1963), a number of patients with this condition have been reported and histopathological, biochemical and virological approaches have been intensively made to elucidate the pathogenesis and etiology of this condi- tion because of high mortality rate and occasional widespread outbreaks.

Because this condition is often preceded by some specific or nonspecific viral illnesses, attention has been payed to virological and serological studies and association of the condition with such viral illnesses, as influenza $B$ infection (Glick et al., 1970 ; Reynolds et al., 1972 ; Linnemann et al., 1970), varicella (Glick et al., 1970) and some other viral illnesses (Schubert et al., 1972) has been known.

\footnotetext{
Abbreviations used :

SGOT : serum glutamic oxaloacetic transaminase

SGPT: serum glutamic pyruvic transaminase

$\mathrm{LDH}$ : lactate dehyrogenase

CPK : creatine phosphokinase

HE : hematoxylin-eosin
} 
No specific single viral agent has, however, been demonstrated to be essentially causative of this condition so far. In some epidemic of this condition in Thailand, etiologic role of aflatoxin was suspected (Olson et al., 1971). We have been interested in this syndrome because "Ekiri" or fulminant dysentery associated with cerebral edema and fatty liver used to occur in Japan and it shared similar features with Reye syndrome.

It seems reasonable now to regard that Reye syndrome is a clinicopathological condition that can be caused by multiple etiologic factors, despite its clinical as well as pathological uniqueness. Although detailed clinical and histological features of this condition are described in Reye et al's original report, diagnostic criteria are not necessarily uniform in cases reported as having Reye syndrome. We describe in the present paper 3 cases with acute encephalopathy and some laboratory and histological evidences of liver damage occurring after prodromal illnesses, and diagnostic value of liver biopsy for Reye syndrome is discussed.

\section{CASES}

Case 1. OPD \#73-1513 Acute encephalopathy with fatty liver

A 1 year and 10 month-old boy was admitted because of seizures. The patient was born to nonconsanguinious healthy parents and was the product of uneventful delivery. Past history was unremarkable except that he suffered from measles at the age of 7 month. He was noticed to have running nose on July 1st, 1973 without cough or fever. On July 10, he appeared to be in ill temper and pale. A few hours later, he was found convulsing in bed, with scream and vomiting. Horizontal eye movement was noticed at that time. He was referred to our Medical Center because tonic seizure recurred on the same day.

On admission, he appeared a fairly nourished, convulsing, dyspneic child in semicomatose state without jaundice. His face was pale, and lips cyanotic. Upon auscultation, stridor and moist rales were audible over the entire lung field. Pupils were round and equal, but constricted and reacted to light slowly. Extraocular movement was within normal limits. The discs were not choked. Deep tendon reflexes were symmetric and diminished. No ankle clonus was elicited, as was no extensor plantar toe reflex. Liver was palpable $0.7 \mathrm{~cm}$ below the costal margin. After admission, he received fluid intravenously and $3 \mathrm{mg}$ of diazepam, by which seizure was diminished but not terminated. Hydrocortisone was given because brain edema was suspected. On the 2nd hospital day, he remained hypotonic and corneal reflex was absent and mannitol and diazepam were administered. Although episodes of seizure subsided by the treatment, symmetric fasciculation of lower extremities was noted, and pupils reacted to light very slowly. Prednisolone, 30 mg daily, was given until death. On the same day, sudden respiratory arrest with following cardiac arrest occurred, which were relieved by resuscitation. Electroencephalographic tracing showed abnormally slow waves at that time. On the 3 rd hospital day, 7 hours after the first cardiorespiratory arrest, respiratory arrest recurred and mechanical ventilation was initiated. Liver was palpable $3 \mathrm{~cm}$ below the costal margin. Liver biopsy was done then. Electroencephalographic tracing was flat. ' $\mathrm{He}$ remained comatose and pupils were dilated, and did not react to light. The state of consciousness and size of liver remained unchanged until 7 th hospital 
day, when cardiac arrest recurred and resuscitation was unsuccessful.

\section{Case 2. OPD \#75-184 Reye syndrome}

A 9 month-old female infant was seen because of vomiting, seizure and disturbance of consciousness. She had been well until January 21, 1975, when she had rhinorrhea. On January $22 \mathrm{nd}$, she vomited 3 times and had diarrhea until January 26 th. On January 23 rd, after fever of $38.9^{\circ} \mathrm{C}$ developed, she had an episode of tonic, symmetric convulsion involving predominantly the upper extremities, which brought her to our Medical Center.

On admission, she presented as a fairly nourished, moderately dehydrated infant who had tonic convulsion in somnolence. The temperature was $37.4^{\circ} \mathrm{C}$, respiration, $64 / \mathrm{min}$. and irregular, with retraction. There was no jaundice. Heart sound was regular without murmur and stridor was heard. The abdomen was distended, and liver was firm and palpable $2 \mathrm{~cm}$ below the costal margin. Deep tendon reflexes were markedly diminished on the right upper and lower extremities and within normal limits on the left extremities. Extensor plantar toe reflex was elicited bilaterally. She gradually became comatose and did not respond to painful stimuli on the 1st hospital day. On the 2 nd hospital day, convulsion subsided and deep tendon reflexes were within normal limits except that right patellar tendon reflex was diminished. Muscular tone recovered on the right extremities but paresis of right lower extremity was noted. The. first liver biopsy was done on the 3 rd hospital day. The state of consciousness became somnolent and she could suck on some occasions. Hydrocortisone, $100 \mathrm{mg} /$ day intravenously, was given. The liver was felt more enlarged on the 4 th hospital day. Prednisolone, $20 \mathrm{mg}$. every 12 hours, was given intravenously instead of hydrocortisone during the following 6 days from the 6 th hospital day. The state of consciousness remained unchanged. Around the 8 th hospital day, state of consciousness began to improve so that she could recognize her mother and suck for herself. Liver became less swollen and palpated $1 \mathrm{~cm}$ below the costal margin. Prednisolone was changed to betamethazone, $1 \mathrm{mg}$ daily, per os. The lower extremities were less active than upper extremities. On the 12 th hospital day, she developed a peculiar movement of the upper extremities ; she repeated to bring her right hand to her mouth, which seemed to be a kind of seizure and diminished in frequency by nitrazepam. The second liver biopsy was done on the 23rd hospital day. She began to crawl and could stand being supported, as she had been able to do before the illness and facial expression became vivid on the 44 th hospital day. She was discharged without any neurological sequelae.

Case 3. OPD \#75-1591 Acute neurological deterioration following chickenpox

This $6 \frac{1}{2}$ month-old male infant was admitted because of convulsion. Past and family histories were noncontributory except that his 5 year-old sister had chickenpox 18 days prior to his admission. On June 12, 1975, he was found to have some papules over the buttock, which extended to face, trunk and extremities and developed into vesicles, further into crusts, typical skin lesions of chickenpox. He developed fever of $38.0^{\circ} \mathrm{C}$ next day and on June $15 \mathrm{th}$, he had an episode of generalized tonic convulsion lasting for 5 minutes. Consciousness was not clear at that time. He was admitted because the episode of seizure recurred on the same 
day.

He appeared a chubby, well nourished infant who was convulsing, dyspneic and grunting in coma on admission. The convulsion was generalized and clonic, with eyes fixed upward. Stridor and moist rales were heard at auscultation. Liver was palpable $3 \mathrm{~cm}$ below the costal margin and felt firm. No jaundice was noted. The pupils were round and equal but reacted to light very slowly. There was no bulging fontanel, nuchal rigidity or choked disc. He showed a decorticate posture and deep tendon reflexes were exaggerated symmetrically, with spastic extremities. Extensor plantar toe reflex was negative. Upon admission, intravenous drip infusion was initiated and diazepam, dexamethazone and cefazolin were given by vein, to which intramuscular phenobarbital was added every 6 hours. On the 2nd hospital day, liver biopsy was performed. The state of consciousness remained comatose or semicomatose. Positive extensor plantar toe reflex was elicited on 2 nd hospital day and seizure tended to recur until the 3 rd hospital day, although decreased in frequency after the anticonvulsants were started.

An electroencephalogram recorded on that day showed low voltage and fast wave over the frontal and central areas. Around the 8th hospital day, consciousness began to improve and eye movements became active. Dexamethazone was discontinued because of emerging hypertension on the 15th hospital day. The extremities gradually become less spastic during the following 1 week. The electroencephalographic tracing was interpreted within normal limits on the 18th hospital day. Consciousness became alert by the 25th hospital day and he could distinguish his mother but head control was incomplete. $\mathrm{He}$ was discharged with slightly increased deep tendon reflexes on the 32nd hospital day.
The laboratory data on admission are summerized in the Table 1 and serum enzyme activity levels and ammonia concentrations during the course of hospitalization in cases 2 and 3 are presented in Figs. 1 and 2.

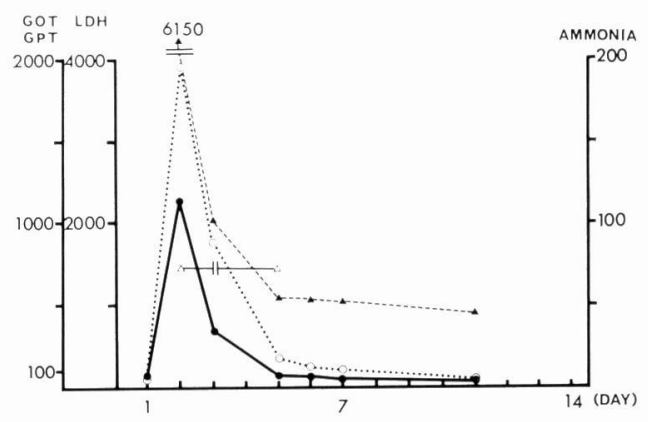

Fig. 1 SGOT, SGPT, LDH activities and blood ammonia concentrations of case 2 during the hospitalization are presented. The left outermost ordinate represents activities of transaminases in Karmen unit, and inner one, LDH activity in Wroblewski unit. Dates of sampling after hospitalization are indicated on abscissa. SGOT $\bullet-$ SGPT $\circ \cdots \cdots \cdot$

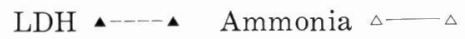

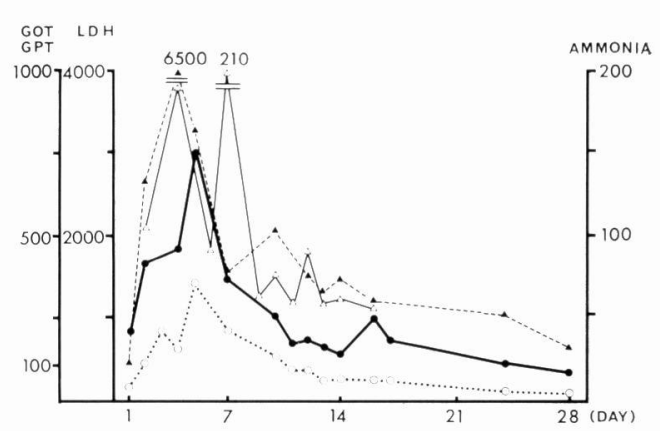

Fig. 2 SGOT, SGPT, LDH activities and blood ammonia concentrations of case 3 during the hospitalization are presented in a same manner as in Fig. 1. 
TABLE 1

Laboratory data on admission ${ }^{+}$

\begin{tabular}{|c|c|c|c|}
\hline & Case 1 & Case 2 & Case 3 \\
\hline Blood sugar $(\mathrm{mg} / 100 \mathrm{ml})$ & $90^{*}$ & 49 & 67 \\
\hline SGOT (Karmen unit) & 146 & 1150 & 405 \\
\hline SGPT (Karmen unit) & 32 & 1950 & 105 \\
\hline LDH (Wroblewski unit) & 2350 & 6150 & $2630 * *$ \\
\hline \multicolumn{4}{|l|}{$\mathrm{LDH}$ isozymes $(\%)$} \\
\hline I & 56.5 & 6.9 & $18.8^{* *}$ \\
\hline II & 29.9 & 12.0 & 21.2 \\
\hline III & 8.6 & 9.9 & 20.6 \\
\hline IV & 2.7 & 12.3 & 17.8 \\
\hline $\mathrm{V}$ & 2.3 & 54.1 & 21.6 \\
\hline Prothrombin time ( $\%$ normal) & 100 & 47 & 36 \\
\hline Total birilubin $(\mathrm{mg} / 100 \mathrm{ml})$ & - & 1.3 & - \\
\hline Ammonia $(\mu \mathrm{g} / 100 \mathrm{ml})$ & - & 75 & 105 \\
\hline Urea nitrogen $(\mathrm{mg} / 100 \mathrm{ml})$ & 36 & 14 & 62 \\
\hline Acid base balance & $\begin{array}{l}\text { Metabolic } \\
\text { acidosis }\end{array}$ & $\begin{array}{l}\text { Metabolic } \\
\text { acidosis }\end{array}$ & $\begin{array}{l}\text { Metabolic } \\
\text { acidosis }\end{array}$ \\
\hline \multicolumn{4}{|l|}{ Electrolytes $(\mathrm{mEq} / \mathrm{L})$} \\
\hline $\mathrm{Na}$ & 147 & 139 & 136 \\
\hline $\mathrm{K}$ & 5.4 & 4.5 & 4.6 \\
\hline $\mathrm{Cl}$ & 99 & 96 & 106 \\
\hline \multicolumn{4}{|l|}{ Spinal fluid } \\
\hline Pressure $\left(\mathrm{mmH}_{2} \mathrm{O}\right)$ & 310 & 270 & 120 \\
\hline Protein $(\mathrm{mg} / 100 \mathrm{ml})$ & 50 & 70 & 50 \\
\hline Glucose $(\mathrm{mg} / 100 \mathrm{ml})$ & 50 & 50 & 50 \\
\hline Cell count $(/ \mathrm{cmm})$ & 5 & 2 & 2 \\
\hline
\end{tabular}

+ Laboratory data on the 2nd hospital day.

* After the initiation of fluid therapy.

** Values on 3rd hospital day.

\section{HISTOLOGY OF THE LIVER}

The liver tissue was obtained by aspiration biopsy with a Menghini needle on the dates specified in the case report. A portion of each specimen was fixed in formalin and stained with hematoxylin and eosin for light microscopy and remaining portion was prefixed in $2.5 \%$ glutaraldehyde and fixed in osmium tetrachloride, then embedded in Epon for electron microscopy in cases 2 and 3.

\section{Light Microscopy}

Case 1 : The disarrangement of hepatocytic cord was seen to the minimum extent. The majority of hepatocytes contained large vacuoles which were suggestive of fat droplet accumulation in the cells. The portal changes were not remarkable (Fig. 3).

Case 2. The 1st biopsy : Focal necrosis of the hepatocytes is noted around the central vein occasionally. Proliferation 
of Kupffer cells is not seen (Fig. 4 a). Most of the hepatocytes appear swollen and contain small vacuoles in the cytoplasm, compatible with fat droplets and the portal areas were slightly infiltrated with mononuclear cells (Fig. 4 b).

Case 2. The 2 nd biopsy: The vacuolization of hepatocytes was still noted to lesser extent. Neither the proliferation of the Kupffer cells nor hepatocytic necrosis was seen (Fig. 5).

Case 3 : Arrangement of hepatocytes was generally well preserved. Some hepatocytes appeared, however, swollen and contained vacuoles within the cytoplasm. The portal areas were normal (Fig. 6).

\section{Electron microscopy}

Case 2. The 1 st biopsy: Numerous small fat droplets, approximately $1-5 \mu$ in diameter, were noted in the cytoplasm of every hepatocytes (Fig. 7 a). Glycogen granules were abundant. Mitochondria with electron lucid matrix, reduced mitochondrial granules or disoriented cisternae were observed in some hepatocytes which were undergoing necrosis. In most of the hepatocytes, however, cytoplasmic organelles including mitochondria were fairly well preserved inspite of the presence of many fat droplets (Fig. 7 b).

Case 2. The 2nd biopsy: In the 2nd biopsy specimen, small fat droplets in the cytoplasm had disappeared, but sinusoidal linning cells with fat droplets were often observed. Proliferated Golgi apparatus, autophagic vacuoles and lipofuscin granules were located in the pericanalicular regions. Occasionally peroxisomes increased in number. The number, size and structure of mitochondria were normal (Fig. 8).
Case 3 : Some hepatocytes showed the accumulation of small fat droplets in the cytoplasm, as were seen in case 1 . The extent of this fatty change varied from cell to cell. Vesicles or dilated smooth-surfaced endoplasmic reticulum were noted and peroxisomes increased in number. Occasionally, mitochondria appeared to be slightly swollen and their matrix was less dense. Mitochondrial structure was, however, well preserved in general (Fig. 9).

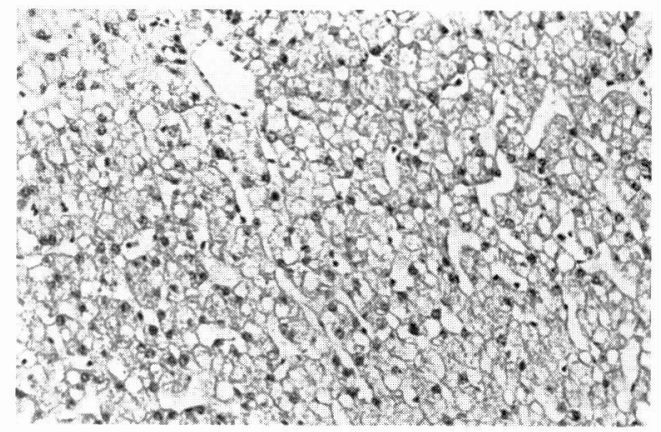

Fig. 3 Liver histology of case 1 (HE-stain, $\times 210$ ). The majority of hepatocytes contain large vacuoles suggestive of presence of huge fat droplet accumulation in the cytoplasm, with displaced nuclei.

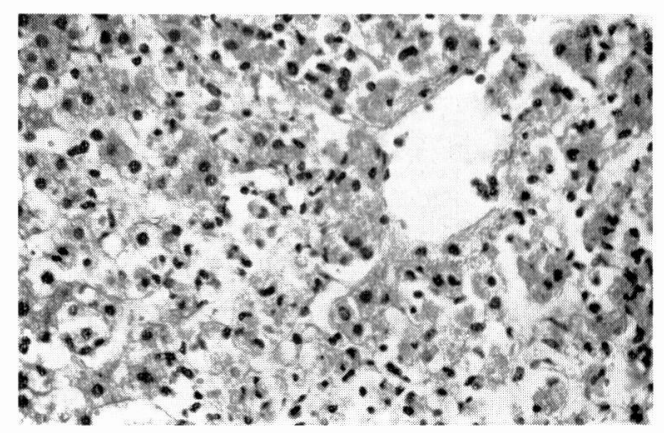

Fig. 4 a Liver histology of case 2, 1st biopsy (HE-stain, $\times 350$ ). Focal necrosis of the hepatocytes is noted around the central vein occasionally. Proliferation of Kupffer cells is not seen. 


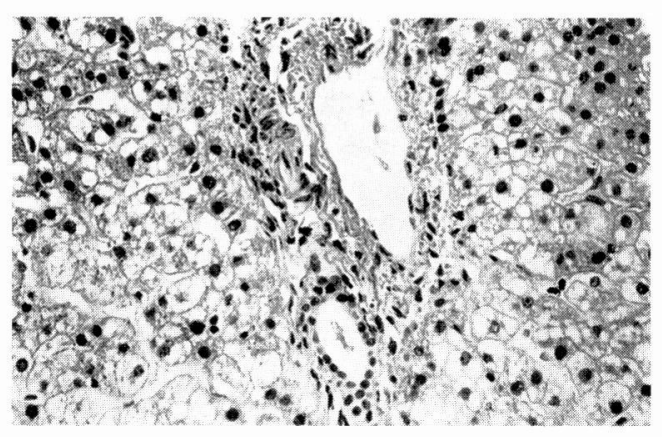

Fig. 4 b Liver histology of case 2, 1st biopsy (HE-stain, $\times 250)$. Most of the hepatocytes appear swollen and contain small vacuoles in the cytoplasm, compatible with fat droplets.

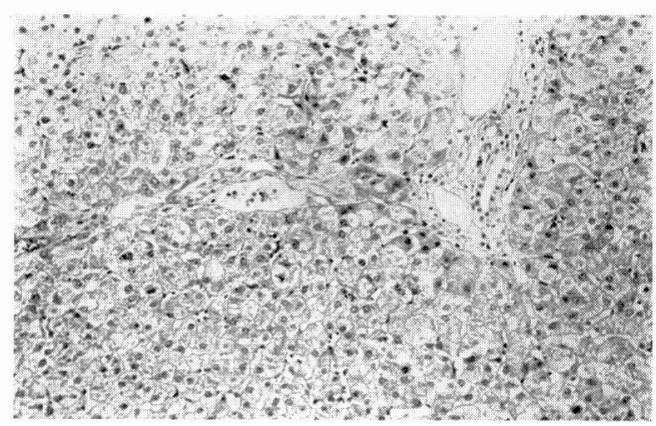

Fig. 6 Liver histology of case 3 (HE-stain, $\times 180$ ). Arrangement of hepatocytes is generally well preserved. Some hepatocytes, however, appear swollen.

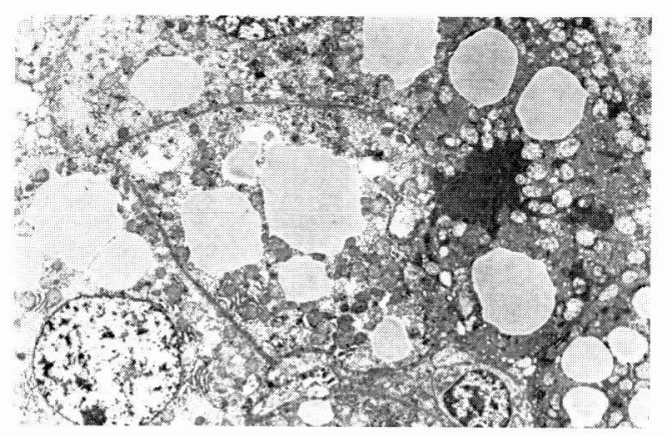

Fig. 7 b Electron micrograph, case 2, 1st biopsy $(\times 1,800)$. Hepatocytes located in the centrolobular area, undergoing necrosis, have irregularly shaped mitochondria with electron lucid matrix. Numerous small fat droplets are also noted.

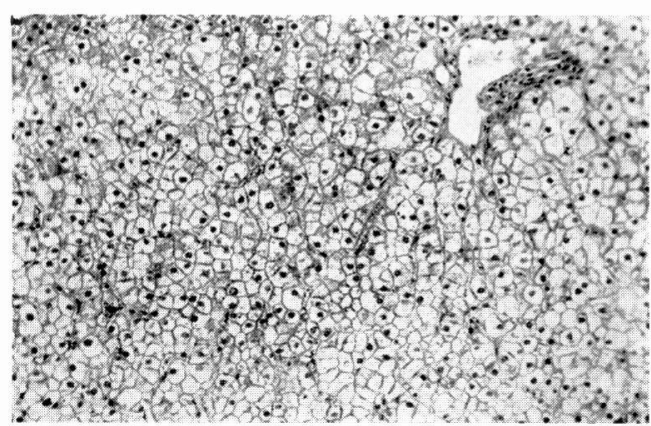

Fig. 5 Liver histology, case 2, 2 nd biopsy (HE-stain, $\times 180)$. The vacuolization of the hepatocytes is still noted to the lesser extent. Neither the proliferation of the Kupffer cells nor hepatocytic necrosis is seen.

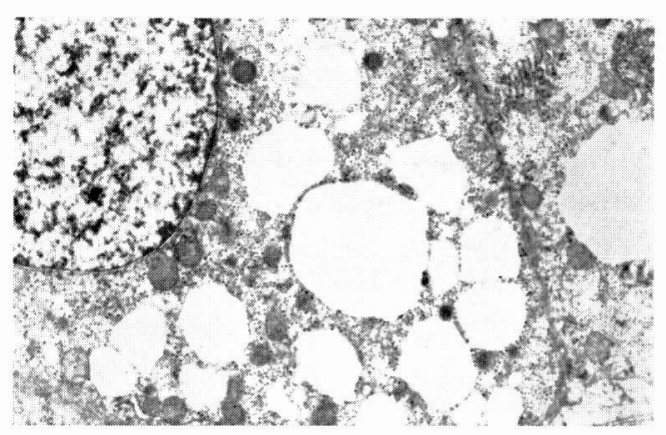

Fig. $7 a$ Electron micrograph, case 2, 1 st biopsy $(\times 4,900)$. Numerous fat droplets are observed in the cytoplasm.

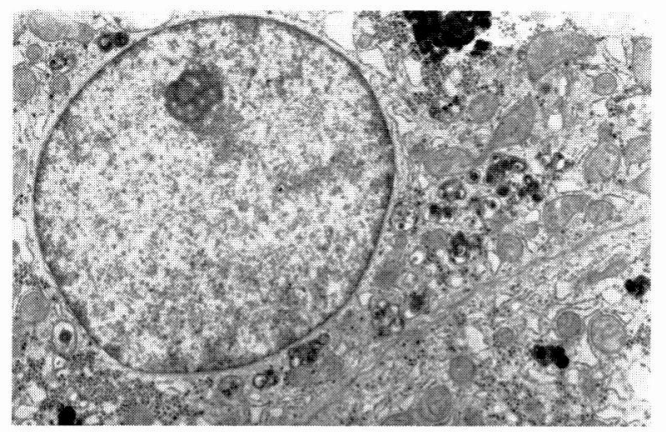

Fig. 8 Electron micrograph, case 2, 2nd biopsy $(\times 4,800)$. Fat droplets had disappeared. Numerous electron dense materials, laminated in appearance, are observed in the cytoplasm. 


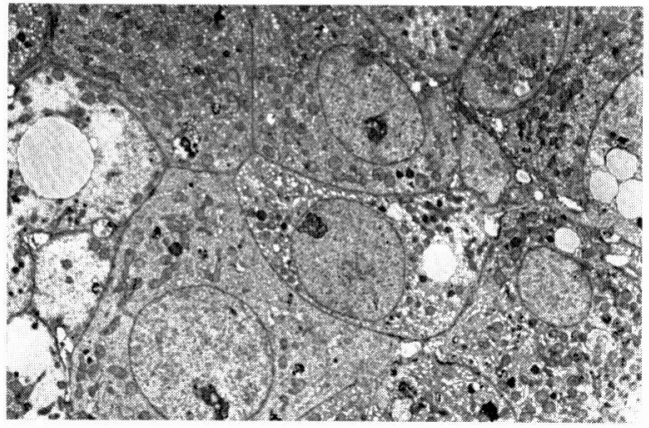

Fig. 9 Electron micrograph, case $3(\times 1,800)$. Few hepatocytes contain fat droplets. Mitochondrial structure is well preserved in the hepatocytes containing fat droplets, too.

\section{DISCUSSION}

There have been no definite clinical diagnostic criteria for Reye syndrome, although typical clinical features of this syndrome are summerized in recent literatures (Glasgow et al., 1972 a ; Partin, 1975). All cases in this series had clinical features and course that are compatible with Reye syndrome except that case 3 had no episode of vomiting. Elevated serum transaminase activities, blood ammonia, prolonged prothrombin time and less frequently hypoglycemia are the major biochemical changes in Reye syndrome (Partin, 1975). Increase in activity of some serum enzymes, such as $\mathrm{LDH}$ or $\mathrm{CPK}$ is also reported (Roe et al., 1975). Transaminases were apparently elevated in cases 2 and 3 , and showed transient course. Case 1 also had high initial SGOT, although successive values were not assessed. In case 2, SGPT was more predominantly elevated unlike other 2 cases. This patient may be included in hepatic group as classified by Roe et al. (1975), although CPK activity and its isozyme pattern were not available. In cases 2 and $3, \mathrm{LDH}$ isozyme pattern was followed, which showed that isozyme V, a hepatic iso- zyme, was markedly increased at initial stage and it returned to normal level on the following day associated with the decrease in total $\mathrm{LDH}$ activity. This observation implies very transient nature of liver damage in Reye syndrome and also in case 3 . A similar increase in $\mathrm{LDH}$ activity was seen in case 1 , too.

Ammonia was increased in case 3 . Although hyperammonemia in this case may be rendered in part to bleeding from intestinal lesion of chickenpox, this may be the outcome of urea cycle dysfunction, as is demonstrated in Reye syndrome (Thaler, 1975), since he passed only scanty tarry stool that would not account for hyperammonemia of that extent. One feature that is not compatible with Reye syndrome in case 2 was the absence of hyperammonemia. Hyperammonemia is, however, not necessarily an outstanding feature in some patients with Reye syndrome, although majority of the patients have hyperammonemia (Huttenlocher, 1972). It is also possible that hyperammonemia might have been overlooked because it occurs very transiently in some cases, falling to a normal value within the first several hours after development of encephalopathy. It is interesting from the standpoint of etiologic role of ammonia intoxication in the pathogenesis of encephalopathy in Reye syndrome that this patient had disturbance of consciousness despite the normal blood ammonia level at initial stage, which suggests hyperammonemia is not the sole etiology of encephalopathy in Reye syndrome, although hyperammonemia can be one of the possible etiologies and it should be kept in mind that high blood ammonia level does not give one insight into ammonia metabo lism in brain, which makes it impossible to relate blood ammonia level to the disturbance of consciousness directly. 
It is noteworthy that rise in transaminases and LDH occurred following development of clinical encephalopathy in case 2 , suggesting that certain common factor(s) might have caused encephalopathy and liver damage monistically, although later clinical course may have been modified by changes in metabolism as the result of hepatic dysfunction.

In the present series, Reye syndrome was suspected clinically also in cases 1 and 3 as tentative diagnosis until liver histology became avilable. The histology of the liver was not, however, consistent with Reye syndrome in cases 1 and 3. Although case 1 had fatty liver, large fat lakes were demonstrated unlike small fat droplets uniformly scattered in the cytoplasm in hepatocytes typically seen in Reye syndrome. Another finding that distinguishes this case from Reye syndrome was that hepatocytic nuclei were displaced irregularily, which is inconsistent with liver histology in Reye syndrome (Partin et al., 1971). In case 2 , both light and electron microscopic appearances of the liver histology were compatible with characteristics described in Reye et al's original report and further detailed observation by some other authors (Schubert et al., 1972 ; Bove et al., 1975). Mitochondrial pleomorphism was, however, not prominent in this patient even in the liver tissue obtained at initial acute stage. Mitochondrial pleomorphism may, however, not be the sine qua non for the histologic diagnosis of Reye syndrome (Svoboda and Reddy, 1975).

Since almost all metabolic disarrangements characterizing this syndrome could be accounted for as the result of mitochondrial dysfunction, morphological change of mitochondria appears to be compatible with biochemical alterations. It is, however, possible that such functional changes of mitochondria may not necessarily be associated with mor- phological changes, if the insult to mitochondria is less severe. In this sense, absence of typical mitochondrial pleomorphism may not exclude the diagnosis of Reye syndrome in case 2 .

The liver histology of case 3 was different from that of Reye syndrome in that fat droplets were seen in some hepatocytes but not in some other, and fat droplets were various in size even in hepatocytes that contained fat droplets. Irregularity in the distribution of fat droplets is not the case with liver histolog y of Reye syndrome. This patient had, however, some features that are common to those of Reye syndrome, such as elevated transaminases, hyperammonemia or initial low blood glucose level, suggesting that pathophysiology in this condition might have shared some metabolic disarrangements with Reye syndrome. One should, however, keep it in mind that observation on $\mathrm{HE}$-stained specimen alone does not give any direct evidence of fat droplet deposion and that fat stain is necessary to demonstrate the presence of fat droplets in the cytoplasm. Furthermore, minute fat droplet accumulation as is seen in Reye syndrome can be demonstrated only by electron microscopy.

We propose from the observations on the 3 cases, that diagnosis of Reye syndrome should not be made until histological evidence is established. A recent report (Gall et al., 1975) refers to conditions that were indistinguishable from Reye syndrome on the basis of clinical observation and laboratory data and the report states liver biopsy should be done to confirm the diagnosis of Reye syndrome. Validity and necessity of liver biopsy for the diagnosis of Reye syndrome is emphasized by another author (Schubert, 1975). It appears that presence of fatty liver as described is necessary for the diagnosis of Reye syndrome at present, as far as substantial 
pathogenesis has not yet been understood, although possibility of nonhistologic diagnosis is presented (Glasgow et al., 1972 b). Studies on such cases as having incompatible histology with typical Reye syndrome presented in the present report or cases without fatty liver (Glasgow et al., $1972 \mathrm{~b}$ ) may give an alternative way to reach the essentials of Reye syndrome, and diagnosis of Reye syndrome may be made without biopsy on the basis of pathogenesis that will be clarified in future.

This work was supported by a grant from the Research Committee for Handicapped Children, Ministry of Health and Welfare of Japan.

\section{REFERENCES}

Bove, K. E., Mc Adams, A. J., Partin, J. C., Partin, J. S., Hug, G. and Schubert, W.K. (1975). The hepatic lesion in Reye's syndrome. Gastroenterology, 69, 685-697.

Gall, D. G., Cutz, E., Mc Clung, H. J. and GreEnBERG, M. L. (1975). Acute liver disease and encephalopathy mimicking Reye syndrome. J. Pediatr., 87, 869-874.

Glasgow, A.M., Cotton, R.B. and Dhiensiri, K. (1972a). Reye's syndrome I. Blood ammonia and consideration of the nonhistologic diagnosis. Amer. J. Dis. Child, 124, 827-833.

Glasgow, A. M., Cotton, R. B., Bourgeois, C. H. and DhiensiRi, K. (1972 b). Reye's syndrome II. Occurrence in the absence of severe fatty infiltration of the liver. Amer. J. Dis. Child., 124, 834-836.

Glick, T. H., Likosky, W. H., Levitt, L. P., Mellin, H. and Reynolds, D. W. (1970). Reye's syndrome: An epidemiologic approach. Pediatrics, 46, 371-377.
Hut tenlocher, P. R. (1972). Reye's syndrome : Relation of outcome to therapy. J. Pediatr. 80, 845-850.

Linnemann, C.C.Jr., Shea, L., Kauffman, C. A. Schiff, G.M., Partin, J.C. and Schubert, W. K. (1974). Association of Reye's syndrome with viral infection. Lancet, 2, 179-182.

Olson, L. C., Bourgeois, C. H., Cotton, R. B., Harikul, S., Grossman, R. A. and Smith, T. J. (1971). Encephalopathy and fatty degeneration of the viscera in northeastern Thailand. Clinical syndrome and epidemiology. Pediatrics, 47, 707-716.

Partin, J. C., Schubert, W. K. and Partin, J.S. (1971). Mitochondrial ultrastructure in Reye's syndrome (Encephalopathy and fatty degeneration of the viscera). N. Engl. J. Med., 285, 1339-1343.

Partin, J. C. (1975). Reye's syndrome (Encephalopathy and fatty liver) Diagnosis and treatment. Gastroenterology, 69, 511-518.

Reye, R.D.K., Morgan, G. and Baral, J. (1963). Encephalopathy and fatty degeneration of the viscera A disease entity in childhood. Lancet, 2, 749-752.

Reynolds, D. W., Riley, H. D., LAFont, D. S., Vorse, H., Stout, L. C. and Carpenter, R. L. (1972). An outbreak of Reye's syndrome associated with Influenza B. J. Pediatr., $80,429-432$.

Roe, C.R., Schonberger, L.B., Gelbach, S.H., Wies, L. A. and Sidbury, J. B. Jr. (1975). Enzymatic alterations in Reye's syndrome : Prognostic implications. Pediatrics, 55, 119-126.

Schubert, W. K., Partin, J. C. and Partin, J. S. (1972). Encephalopathy and fatty liver (Reye's syndrome). Prog. Liver Dis., 4, 489-510.

Schubert, W.K. (1975). Commentary : Diagnosis of Reye syndrome. J. Pediatr., 87, 867.

Svoboda, D. J. and Reddy, J.K. (1975). Pathology of the liver in Reye's syndrome. Lab. Invest., 32, 571-579.

Thaler, M. M. (1975). Pathogenesis of Reye's syndrome: A working hypothesis. Pediatrics, 56, 1081-1084. 